\title{
The Effects of Voltage and Suction Line Heat Exchanger on a Domestic Refrigerator's Performance
}

\author{
Xerri Stefan and Farrugia Mario \\ Mechanical Engineering Department, University of Malta, Msida MSD 2080, Malta
}

Received: July 20, 2016 / Accepted: August 02, 2016 / Published: October 31, 2016.

\begin{abstract}
This experimental analysis shows the measured reduction in energy consumption as well as the effects of voltage on cycle temperatures, pressures, flow rates and also compressor speed (revolutions per minute). The domestic refrigerator used R134a as refrigerant. Two energy consumption procedures were adapted from the JIS and ISO standards. The biggest difference between two standards is that the fridge is not opened in the ISO test while it is opened a number of times in the JIS test. The tests were carried out between $190 \mathrm{~V}$ and $250 \mathrm{~V}$ in steps of $10 \mathrm{~V}$. The reduction in energy consumption was of $49.78 \mathrm{~W} \cdot \mathrm{h}$ per day or $6.27 \%$ of the total consumption. The experiments also showed that the voltage drop resulted in only a small rpm drop which in turn did not result in a noticeable refrigerant flow-rate change. Consequently the temperatures and pressures were not affected.
\end{abstract}

Key words: Refrigeration, voltage optimization, energy consumption, capillary-tube/suction-line heat exchanger.

\section{Introduction}

Energy efficiency and legislation are driving the industry to find ways to reduce the energy consumed by appliances. One way of reducing the energy consumption of a given appliances is the reduction of the supply voltage to the appliance. This is being studied on a network scale and is known as Conservation Voltage Reduction [1]. On a domestic level, there are various products termed as VOS (voltage optimization systems) which reduce the mains voltage to $220 \mathrm{~V}$. One company supplying such product claims that for a class A refrigerator a $16 \%$ decrease in energy consumption can be achieved [2].

Research work at the University of Malta focused mainly on air-conditioning [3-5] and investigation on refrigerators is quite unique at the University. The intra-cycle heat exchanger, not used in air-conditioners, that is however typical in refrigerators provided an additional challenge in the instrumentation and

Corresponding author: Farrugia Mario, Ph.D., senior lecturer, research fields: thermofluids, internal combustion engines, heat transfer, mechatronics, electronic engine controls and power generation. analysis. This intra-cycle heat exchanger increases the performance of the refrigerator, by increasing the refrigerating effect with a negligible increase in the work input required [6]. This is achieved by exchanging heat between the capillary tube and the liquid leaving the condenser with the suction line. The benefit of using such heat exchanger depends on the refrigerant. In some cases, such heat exchanger may cause a decline in performance. Such heat exchangers can also help to protect the system components mainly the compressor by ensuring that no carry over liquid is supplied to the compressor. Two types of such heat exchangers are used and known as capillary-tube/suction-line heat exchanger and liquid-line/suction-line heat exchanger.

The main objectives of this research were to:

- Add the necessary instruments to a refrigerator.

- Analyse the effects of voltage reduction on a domestic refrigerator, in terms of cycle temperatures, pressures and flow rates while taking note of any reduction in energy consumption.

- Note any effects of voltage on a compressor.

- Remove the capillary-tube/suction-line heat 
exchanger from the given refrigerator and analyse its effects on the cycle.

\section{Appliance Energy Efficiency}

\subsection{Energy Consumption Standards}

To compare the energy consumption of different refrigerators, different standards are used. The experimental procedures of this research work followed ISO15502 and JIS C9801. These two standards are very similar to each other. Both require the use of an enclosure so that the refrigerator is protected from air currents. The enclosure is to be made out of wood 16-30 mm thick. This enclosure should be 0.3 meters wider on each side of the refrigerator and at least 0.3 meters higher than the refrigerator. The back of the enclosure should rest against the stops of the refrigerator. This enclosure should not have a front and a top. The insides of the enclosure are to be painted dull black. Both standards required the energy consumption test to be carried over 24 hours.

These two standards differ on the ambient temperatures and test conditions. The ISO standard requires an ambient temperature of $25{ }^{\circ} \mathrm{C}$ for all climates except for tropical zones for which the temperature is to be $32{ }^{\circ} \mathrm{C}$. The humidity must be less than $75 \%$ and the average cabinet temperature is to be $5{ }^{\circ} \mathrm{C}$. For all-refrigerator cabinet, the cabinet (food compartment) is to be empty and the test must not include door openings.

The JIS, on the other hand, requires two tests at different temperatures, one at $15{ }^{\circ} \mathrm{C}$ and one at $30^{\circ} \mathrm{C}$, and the relative humidity is to be $70 \%$ and $55 \%$, respectively. The average consumption is found by assuming 185 days at the low temperature and 180 days at $30{ }^{\circ} \mathrm{C}$. The test should include 35 door openings each held at $10 \mathrm{~s}$ open at $8 \mathrm{~min}$ intervals. At the fourth door opening 0.5 litres of water should be added in the cabinet for every 75 litres of capacity. The average cabinet temperature shall be less than $4{ }^{\circ} \mathrm{C}$.

\subsection{Factors Affecting Energy Consumption}

Research carried out by Grimes et al. [7] concluded that the consumption is affected most by a change in temperature and by the thermostat setting. An increase of $8.3{ }^{\circ} \mathrm{C}$ in ambient temperature resulted in $38 \%$ increase in consumption. The increase in consumption at higher temperatures is a result of higher heat leakage through the insulation and decrease in efficiency of the compressor at higher temperatures.

The frequency of door openings also increases the consumption as a result of cool air trapped inside the refrigerator being exchanged by warm moist air. Heat load is also increased by heat and vapour being transferred onto the surface of the cabinet (food compartment) while open.

The effect of food loading in a refrigerator cannot easily be quantified as it depends mainly on the water content of the food and when fresh food is loaded, it is left for a couple of days in the refrigerator thus the consumption is divided over a number of days. Saidur et al. [8] concluded that $1 \mathrm{~kg}$ of water at $25{ }^{\circ} \mathrm{C}$ increases the consumption by $90 \mathrm{~W} \cdot \mathrm{h}$ for a refrigerator of $135 \mathrm{~L}$ capacity.

\subsection{Effect of Voltage on Refrigerators}

Hood [9] investigated the effect of voltage on the power and energy consumption of a refrigerator. It was concluded that an increase of $10 \%$ voltage will result in 5\% increase in active power, while for a relatively old freezer by $10 \%$. Testing the energy consumption over one week Hood noted that the energy consumption remains practically the same, the reason being that a refrigerator is controlled by a thermostat and a decrease in power resulted in a longer cycle time which counteracted the lower power.

Research by Caruana et al. [10] also concluded that a decrease in voltage will result in a lower instantaneous power of a refrigerator and an increase in cycle time. A test of energy consumption was carried out over a range of appliances typically found in domestic use. For a given load mix including a 
refrigerator, florescent tubes and kettle a decrease of $7.9 \%$ in energy consumption resulted from a drop of $12 \mathrm{~V}$ from $240 \mathrm{~V}$ and $8.7 \%$ by a drop of $25 \mathrm{~V}$.

\subsection{Intra-Cycle Heat Exchangers}

Two different types of intra-cycle heat exchangers are used to augment the basic refrigeration cycle for a domestic refrigerator. These are known as CTSL-HX (capillary-tube/suction-line heat exchanger), and LLSL-HX (liquid-line/suction-line heat exchanger).

The LLSL-HX exchanges heat between the hot liquid refrigerant leaving the condenser and the cool dry/wet vapour leaving the evaporator. This heat exchange sub-cools the liquid leaving the condenser and super-heats the gas leaving the evaporator. This modification ensures that no carry over liquid enters the compressor, and at the same time increases the refrigerating effect of the evaporator as the refrigerant enters the evaporator at lower quality. This heat exchange also prevents gas formation at the entrance of the expansion device [11].

In small refrigeration systems a CTSL-HX is used more often because of its simplicity and low cost. The heat exchange occurs between the capillary tube and the suction line. The capillary tube expansion process is now non-adiabatic. There are two types of CTSL-HX, the concentric and the lateral type. In the concentric configuration the capillary tube passes through the suction line, while for the lateral type the capillary is soldered onto the suction line. Both form a counter flow heat exchanger. The added benefit of this heat exchange is again that the refrigerating effect is increased and prevents liquid refrigerant flowing to the compressor. The capillary also increases the temperature of the suction line above the dew point of air preventing water from condensing on the suction line. The capillary tube when used as a heat exchanger will be divided into three sections: the first part is adiabatic, in the middle part heat exchange occurs and the end part is again adiabatic. The flow inside the capillary tube flashes in the entrance region, where it re-condenses in the heat exchange section and at the outlet it flashes again [12].

In both cases, the LLSL-HX and CTSL-HX, it has to be noted that the temperature of the refrigerant entering the compressor is increased therefore the work input to the compressor increases. This effect may be counteracted by the increase in refrigerating effect. Whether the coefficient of performance, COP, and the volumetric capacity of the system increases or not depends on the refrigerant properties. Although the COP may increase, the cooling capacity of the system may reduce as a result of the mass flow rate of the system reducing. This happens as a result of the refrigerant entering the compressor at higher temperature, thus at larger specific volume. Since compressors are of fixed volume, the intake mass at higher temperature is lower [11]. From theoretical calculations it can be concluded that with use of LLSL-HX a gain in COP is obtained for R134a and a reduction in performance for $\mathrm{R} 717$.

\section{Experimental Setup}

\subsection{Energy Consumption Procedure and Refrigeration Cycle Variation Experiments}

A refrigerator using $\mathrm{R} 134 \mathrm{a}$ as refrigerant, having a capacity of $150 \mathrm{~L}$ and power rating of $100 \mathrm{~W}$ was used in the experiments. The refrigerator was housed in an enclosure with a clearance of $6.5 \mathrm{~cm}$ at the back and $4 \mathrm{~cm}$ on the sides. These specifications are smaller than those specified by the standards. The enclosure was made smaller than that required by the standard to protect the refrigerator from air currents and from rapid changes in ambient temperature. These enclosure clearances were also more indicative of typical clearances found in kitchen installations.

Thermocouples were added at the following locations:

- Compressor inlet;

- Compressor outlet/condenser inlet;

- Condenser outlet;

- Evaporator inlet; 
- Evaporator outlet.

A thermocouple was located near the condenser to measure the ambient temperature inside the cabinet together with three thermocouples inside the refrigerator to measure the average cabinet temperature. The temperatures were recorded using a Keithley 2701 data logging system.

Two pressure gauges were added: one at the high side and one at the low side. A flow meter was modified to read the required flow rate. The flow meter was modified by changing the bob from a spherical one made of steel to a one made out of PTFE (polytetrafluoroethylene) having a cylindrical shape. The new bob had a larger frontal area and lower weight, thus the mass flow rate that the flow meter was capable to read was reduced. Before installing the flow meter, it was calibrated using water and the flow rate was converted to refrigerant flow rate using,

$$
Q_{r}=Q_{f} \times \sqrt{\frac{\rho_{f}}{\rho_{r}}} \times \sqrt{\frac{\rho_{b}-\rho_{r}}{\rho_{b}-\rho_{f}}}
$$

where, $Q$ is flow rate, and $\rho$ is density and subscripts are: $b$-bob, $r$-refrigerant, $f$-water.

Eq. (1) is the flow rate conversion for refrigerant, as calibrated by water.

The refrigerator was operated on an AC UPS (uninterrupted power supply) to supply a steady voltage, and the UPS output voltage was varied using a variac [13].

\subsection{RPM Test}

A similar compressor to the one installed in the refrigerator was opened to reveal the rotating shaft so that the rotational speed of the shaft could be measured using a tachometer. A pressure gauge and a valve were added to the compressor outlet to regulate the outlet pressure on the compressor and thus load the compressor to any desired pressure.

\section{Experimental Procedure}

\subsection{Energy Consumption Procedures}

Two energy consumption procedures were used, one following the JIS standard and the other one following the ISO standard.

The test following the JIS standard was adapted to simulate more realistic conditions. One modification to the standard was to add $18 \mathrm{~L}$ of water inside the refrigerator cabinet. The thermostat of the refrigerator was set at a setting of 3 . A test was started when the compressor switched on and terminated after 24 hours or when the compressor switched off after the 24 hours. When the test was finished, the energy consumption was noted. A series of door openings was initiated after 2 hours the test was started. In total 18 door openings were carried during the first set, opening the refrigerator door at $90^{\circ}$ once every 8 minutes. When the first set was carried out the refrigerator was left closed for 2 hours after which a second set of door openings was carried out. This time 17 door openings were carried out. On the forth door openings of each set, $1 \mathrm{~L}$ of water was replaced by new and warmer water. During the first few door openings ice was scraped off the back of the refrigerator cabinet to keep the amount of ice build-up low. This test was carried out between $190 \mathrm{~V}$ and 250 $\mathrm{V}$ in steps of $10 \mathrm{~V}$.

The experiment following the ISO standard was similar to the one above but the refrigerator was unloaded and unopened during the test. The refrigerator was set at a setting of 1 and the experiments were carried out between $190 \mathrm{~V}$ and 250 $\mathrm{V}$ in steps of $15 \mathrm{~V}$.

\subsection{Refrigerant Properties Variation}

Using the same setup of the energy consumption procedure the variation of refrigerant flow rate, pressures and temperatures was measured. The test was carried out between $1 \mathrm{pm}$ and $5 \mathrm{pm}$ when it was deemed that the ambient temperature varied the least at the laboratory. The measurements taken are listed below.

- Refrigerant temperatures;

- Pressures; 
- Mass flow rate;

- Humidity;

- Instantaneous power;

- Electrical current.

The temperatures were collected automatically every 2 seconds using the Keithley 2701, however the remaining measurements were taken manually. The pressures were grouped together and the power, current and flow rate were considered as another group. Every 20 seconds one group of properties was measured within a 10 second time frame. Readings were taken between $190 \mathrm{~V}$ and $250 \mathrm{~V}$, in voltage steps of $15 \mathrm{~V}$.

This procedure was repeated with the capillary-tube/suction-line heat exchanger removed, by by-passing it using an added pipe. This experiment was only carried out at $235 \mathrm{~V}$.

\subsection{RPM Test}

This test was divided into three parts. For the first part the voltage was varied in steps of $10 \mathrm{~V}$ between $170 \mathrm{~V}$ and $250 \mathrm{~V}$ at no outlet pressure. At each voltage step the RPM was noted.

For the second part the outlet pressure was regulated at 5 bar at each voltage step between $170 \mathrm{~V}$ and $250 \mathrm{~V}$ each time measuring the RPM using the tachometer.

For the third part, the pressure was set at 10.4 bar at $250 \mathrm{~V}$ and the RPM measured. Then the voltage was dropped in steps of $10 \mathrm{~V}$ each time measuring the RPM and pressure. This procedure of keeping the valve setting fixed and recording of the resulting pressure was adopted due to the fact that the valve did not provide enough control to maintain constant pressure.

\section{Results}

\subsection{RPM Test}

The rotational speed of the compressor was noted to reduce as the voltage drops, as expected. As shown in Fig. 1 for no pressure across the compressor the RPM reduced by only 10 RPM between voltages of
$170 \mathrm{~V}$ and $250 \mathrm{~V}$. The decrease in RPM is more pronounced as the pressure across the compressor increases. At 5 bar pressure difference across the compressor, for the same voltage variation, resulted in 60 RPM reduction.

As described above, the highest pressure test was carried out by setting the compressor at 10.4 bar when the voltage was at $250 \mathrm{~V}$ and the valve was not regulated with each voltage drop. It was noted, that a reduction in voltage also resulted in a pressure decrease. This is shown in Fig. 1. A drop of $80 \mathrm{~V}$ results in 0.4 bar loss in pressure and a decrease of 66 RPM. It was also noted that the compressor was not able to start rotating at voltages lower than $130 \mathrm{~V}$.

\subsection{Refrigerant Properties}

Analysis of pressures, temperatures and flow rates at different voltage settings showed no relation between the voltage applied and these properties. Reciprocating compressor theory suggests that as the RPM goes down as a result of voltage reduction, the mass flow rate should also reduce. However as the reduction in RPM was minimal the decrease in flow rate was not noted. Consequently the other properties were also not effected much as the mass flow reduction was not appreciable.

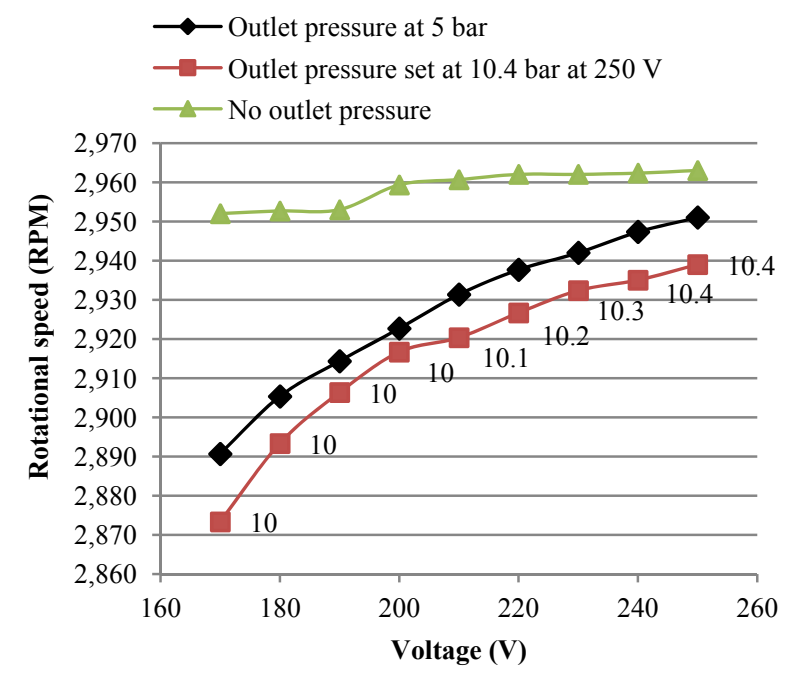

Fig. 1 RPM variation with voltage. 


\subsection{Energy Consumption}

Figs. 2 and 3 plot the variation of energy consumption over 24 hours with voltage. The results of Fig. 2 are those carried out without door openings, adopted from the ISO standard, while those of Fig. 3 were carried out with door openings and water loading inside the refrigerator, adopted from the JIS standard. The numbers shown near each point in Fig. 3 show the number of failed compressor starts.

The number of failed compressor starts is a result of frequent door openings. Frequent door openings increase the temperature inside the cabinet. This triggers the compressor to switch on more frequently. The increased frequency does not allow the refrigerant pressures, at the high and low side, to equalize after the compressor switches off, thus the compressor tries to switch on with a pressure difference across it. More power is required by the compressor to start at a pressure difference, and thus it does not start. A second attempt, a few minutes later, will give enough time for the pressures to equalize and thus the compressor starts rotating.

The energy consumption graph in Fig. 2 is divided into three groups, each group having energy consumptions at different voltages which had approximately equal ambient temperatures. This was done to understand the effect of voltage on consumption at equivalent conditions, since the tests were not carried out in a controlled environment. Fig. 3 is also divided into different groups, this time groups with similar number of failed compressor starts, to eliminate the effect of the energy consumed when the compressor tried to start but failed thus not causing cooling. In this graph the effect of ambient temperature is ignored.

It can be easily noted from the graphs that the energy consumption does decrease with a decrease in voltage. The most reliable results, which had the most comparable ambient temperatures, obtained from the experiments following the ISO standard were between voltages of $205 \mathrm{~V}$ and $250 \mathrm{~V}$ which resulted in a drop in consumption of $12.4 \mathrm{~W} \cdot \mathrm{h}$. A drop in voltage between $190 \mathrm{~V}$ and $235 \mathrm{~V}$ also results in $9.9 \mathrm{~W} \cdot \mathrm{h}$ drop in consumption. The results in Fig. 3 are more difficult to analyse, and the only conclusion which can be drawn up is that between $200 \mathrm{~V}$ and $240 \mathrm{~V}$ resulted in a drop in consumption of $78.6 \mathrm{~W} \cdot \mathrm{h}$. Factoring out the $2.41{ }^{\circ} \mathrm{C}$ increase in temperature at $240 \mathrm{~V}$ over 200 $\mathrm{V}$, results in a decrease in consumption of $46.3 \mathrm{~W} \cdot \mathrm{h}$. Although the effect of ambient temperature was not studied it was noted that at $205 \mathrm{~V}$, during the experiment without door openings, an increase of $1{ }^{\circ} \mathrm{C}$ resulted in an increase in consumption of 13.2 $\mathrm{W} \cdot \mathrm{h} /$ day. Thus the correction was applied by using simple proportion.

Fig. 4 shows a plot of the energy consumption at different voltages using the results obtained in the experiments without door openings. That is Fig. 4 is a simplification of Fig. 2. The results in Fig. 4 are corrected for ambient temperature using simple proportion as already explained. A total of 11.52 $\mathrm{W} \cdot \mathrm{h} /$ day is saved by dropping the voltage from $250 \mathrm{~V}$ to $190 \mathrm{~V}$. It has to be noted that the correction was made using data collected at $205 \mathrm{~V}$, and any reduction in energy consumption as a result of change in ambient temperature may have different results at different temperatures. The full effect of ambient temperature could not be studied as we had no control over ambient temperature.

Corrections on the experimental results were carried out to factor out the effects of ambient temperature and door openings. A maximum drop in energy consumption was registered between $200 \mathrm{~V}$ and $240 \mathrm{~V}$. The reduction was of $49.78 \mathrm{~W} \cdot \mathrm{h}$ or $6.27 \%$ of the total consumption.

These small differences in consumption are negligible when converting them into $\mathrm{kW} \cdot \mathrm{h}$, which is the billable unit. Considering the price of electricity of say $0.20 €$, a saving of $3.41 € /$ year is registered for the tested refrigerator, calculated for the highest drop in energy consumption. 


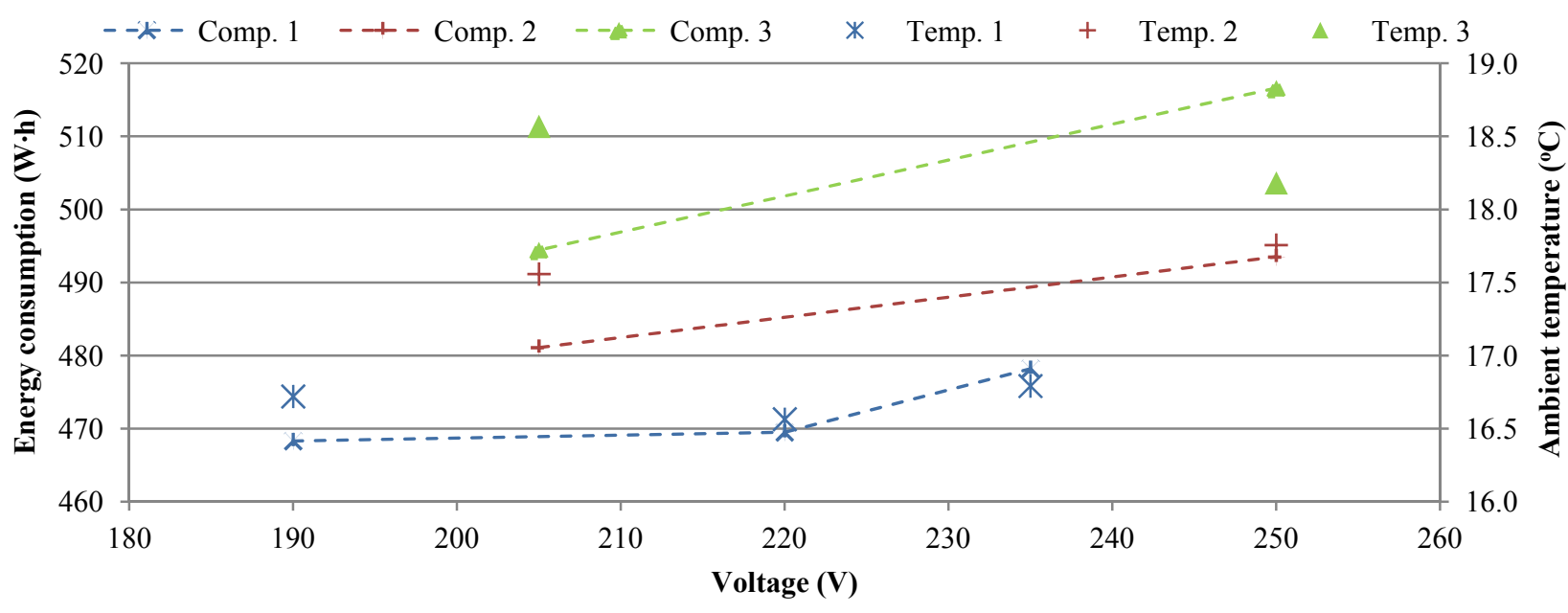

Fig. 2 Energy consumption variation with voltage for the experiments without door openings. Experiment at $205 \mathrm{~V}$ and 250 V were carried out twice.

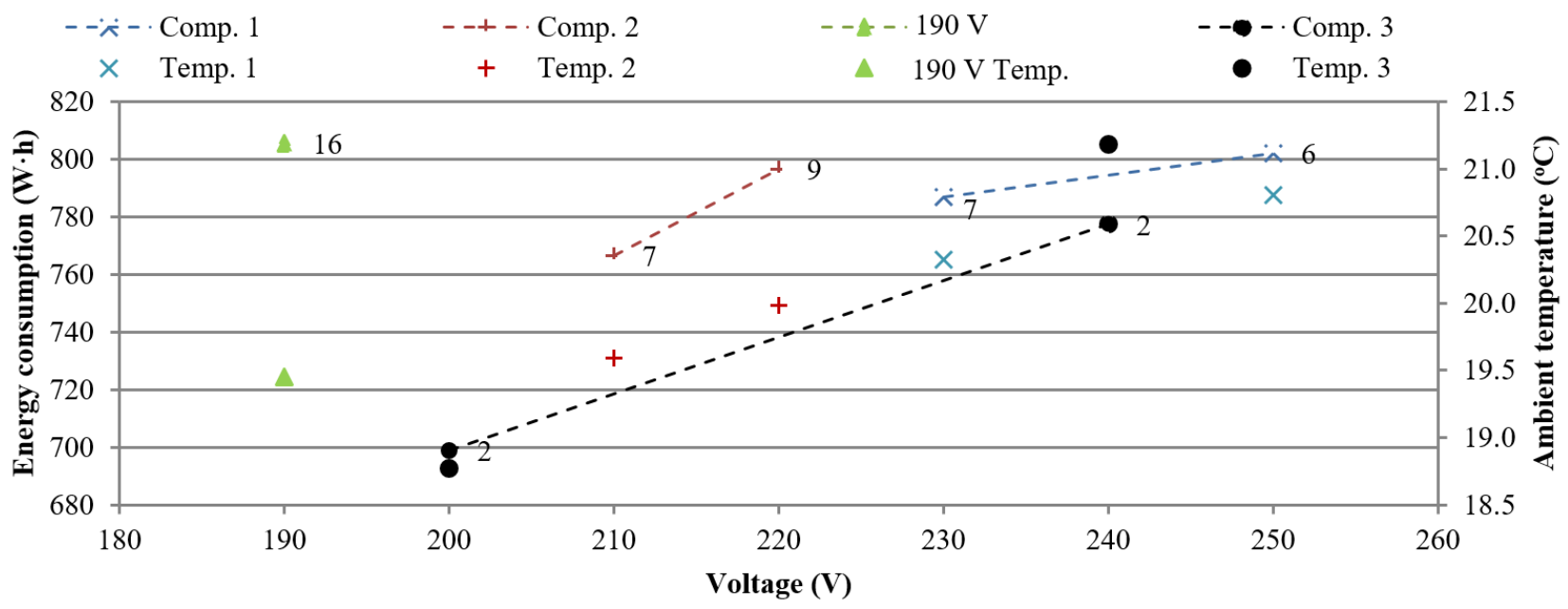

Fig. 3 Energy consumption variation with voltage for the experiments with door openings.

In Figs. 2 and 3, the lines mark the energy consumption, while the individual points mark the corresponding ambient temperature, at the given test, read from the secondary axis. (Legend summary: Comp.-comparison, Temp.--temperature). The points at the end of the lines mark the energy consumption reading at the given voltage. Points at similar conditions (same temperature or same number of compressor starts) were paired for easier visualisation of the results.

The instantaneous power variation with voltage was analysed and is plotted in Fig. 5. It was noted that the compressor ON-time between $190 \mathrm{~V}$ and $250 \mathrm{~V}$ only varies by an average of 8 seconds, at $190 \mathrm{~V}$ the compressor remains on for a longer time. Nothing that this has negligible effect on the energy consumption, using trapezoidal rule on the data of Fig. 5 it was deduced that over a day the consumption varies at the estimate shown in Fig. 6.

During the experimentation, it was noted that the refrigerant temperature at the compressor outlet cannot be measured accurately by attaching a thermocouple on the outlet pipe of the compressor. This is a result of heat exchange occurring between the discharge pipe and the muffler inside the reciprocating compressor with the refrigerant encapsulated in the dome. 


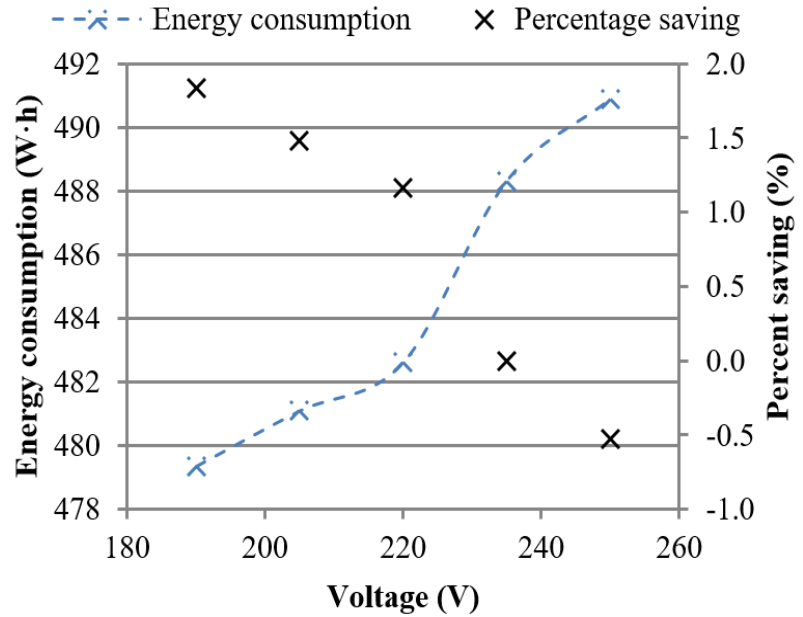

Fig. 4 Energy consumption corrected for the effects of ambient temperature variations.

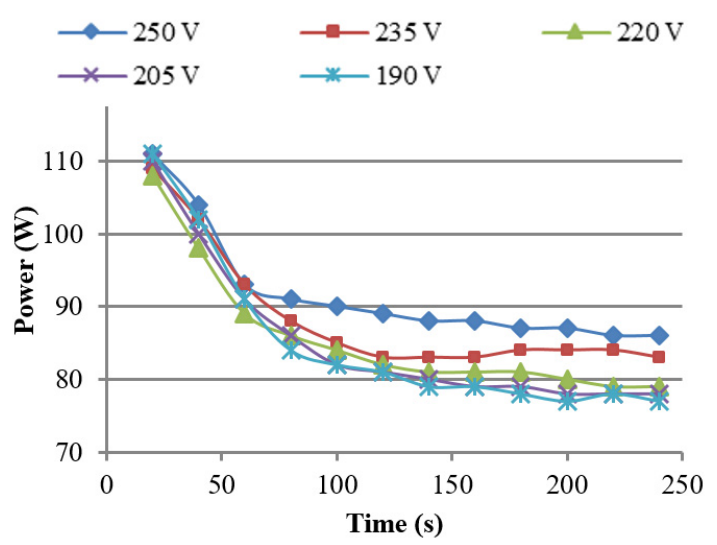

Fig. 5 Instantaneous power variation with voltage.

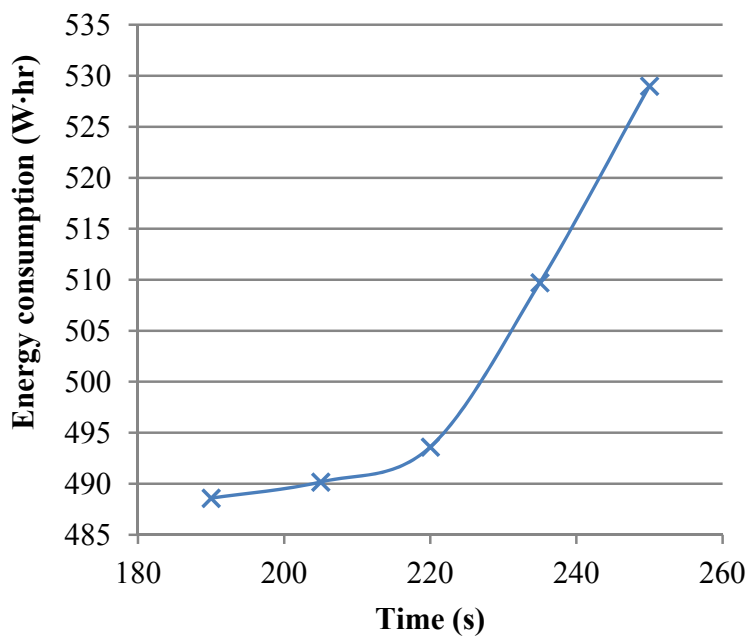

Fig. 6 Estimated energy consumption in 24 hours.

A simple heat transfer analysis on the discharge pipe using natural convection showed that $6.31 \mathrm{~W}$ of heat loss was estimated. Together, the discharge muffler and pipe cause a heat loss of $13.93 \mathrm{~W}$, thus the temperature read at the outlet pipe was estimated to be around $40{ }^{\circ} \mathrm{C}$ lower than the true refrigerant discharge temperature of the compressor. Furthermore, the heat losses in the discharge muffler were not considered in the heat transfer analysis as it could not be accessed easily.

\subsection{CTSL-HX}

The refrigerator used during the experiments employed a CTSL-HX. This was removed at the end of the research work to analyse its effect on the system performance. Fig. 7 shows the increase in performance by using the CTSL-HX. The refrigerating effect was shown to be considerably higher by use of suction-line heat exchange. The compressor work was calculated assuming an isentropic compression. From Fig. 7 and taking note that the flow rate did not change with or without use of the heat exchanger it can be noted that as a result of the reduced refrigerating effect, the cycle without the CTSL-HX takes longer to produce the same refrigerating effect. The cycle is 22 seconds longer without the CTSL-HX.

Another benefit of using the CTSL-HX is the noted $13{ }^{\circ} \mathrm{C}$ increase in superheat of the refrigerant at the compressor inlet. This boils any liquid that may have not evaporated inside the evaporator.

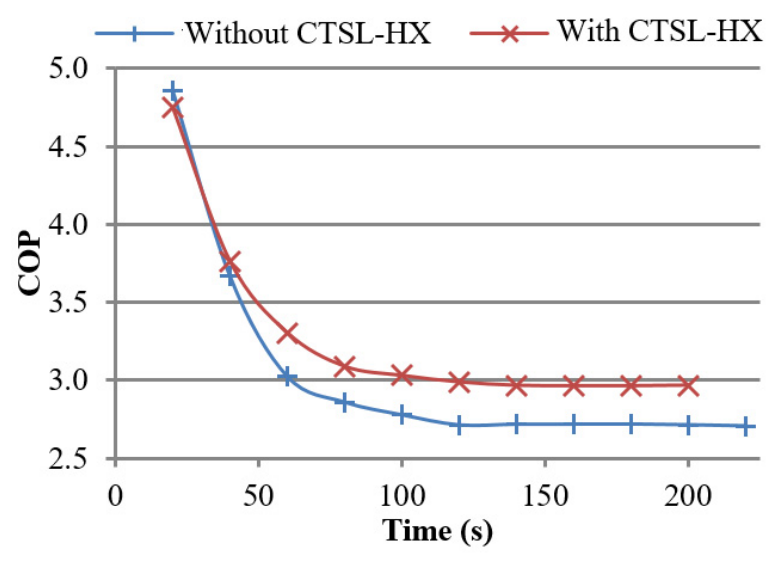

Fig. 7 COP increase with the use of CTSL-HX. 


\section{Conclusions}

From this experimental work, it was noted that a decrease in voltage will result in a small decrease in energy consumption. In our case the drop in energy consumption was small and does not justify the use of VOS. For larger domestic refrigerators the benefit could be greater and the use of VOS may be justified.

The drop in voltage did not change the cycle temperatures, pressures and flow rates. It however reduced the RPM of the compressor by about $60 \mathrm{RPM}$ at a drop of $80 \mathrm{~V}$.

The use of CTSL-HX is justified in refrigeration systems using R134a as the COP and refrigerating effect increase. It also protects the compressor from slugging.

\section{Acknowledgments}

The technical assistance by Andrew Briffa of the Thermodynamics Laboratory was vital in this work. The financial support of the University of Malta Research Fund is acknowledged.

\section{References}

[1] Schneider, K. P., Fuller, J., Tuffner, F., and Singh, R. 2010. Evaluation of Conservation Voltage Reduction (CVR) on a National Level. Pacific Northwest National Laboratory report.

[2] V Phase, Saving Electricity \& Home Energy with V Phase. 2013. Accessed March 3, 2013. http://www.vphase.co.uk/How-It-Works/What-savings-ca n-I-make.

[3] Grech, N., and Farrugia, M. 2012. "Experimental Investigation of Variable Speed Operation of Air Conditioning." In Proceedings of the 9th International Conference on Heat Transfer, Fluid Mechanics and Thermodynamics, 1674-82.

[4] Zammit, K., and Ghirlando, R. 2012. "Improving the
Energy Efficiency of a Control Cabinet Air Conditioner through the Use of Variable Refrigerant Flow Capacity Control." In Proceedings of the 9th International Conference on Heat Transfer, Fluid Mechanics and Thermodynamics, 1666-73.

[5] Fenech, G., and Farrugia, M. 2014. "Experimental Analysis of a Fixed Speed and Variable Speed Air Conditioning System." In Proceedings of the 20th International Conference Engineering Mechanics, 179-82.

[6] Domanski, P. A., Didon, D. A., and Doyle, J. P. 1992. "Evaluation of Suction Line-Liquid Line Heat Exchange in the Refrigeration Cycle" In Proceedings of International Refrigeration and Air Conditioning Conference, 487-93.

[7] Grimes, J. W., Mulroy, W., and Shomaker, B. L. 1977. "Effect of Usage Conditions on Household Refrigerator-Freezer and Freezer Energy Consumption." In Symposium of ASHRAE Transactions, D-CH-77-13-3.

[8] Saidur, R., Masjuki, H. H., and Mahlia, T. M. I. 2002. "Factors Affecting Refrigerator-Freezers Energy Consumption." ASEAN Journal Science and Technology Development 19 (2): 57-67.

[9] Hood, G. K. 2004. "The Effects of Voltage Variation on the Power Consumption and Running Cost of Domestic Appliances." In Proceedings of Australian Universities Power Engineering Conference, 26-9.

[10] Caruana, C., Yousif, C., and Debono, M. 2013. "Testing the Potential of Voltage Reduction for Achieving Higher Energy Efficiency." In Proceedings of the ISE Annual Conference Sustainable Energy, 54-62.

[11] Klein, S. A., Reindl, D. T., and Brownell, K. 2000. "Refrigeration System Performance Using Liquid-Suction Heat Exchangers." International Journal of Refrigeration 23 (8): 588-96.

[12] Hermes, C. J. L., Melo, C., and Gonçalves, C. M. 2008. "Modeling of Non-adiabatic Capillary Tube Flows: A Simplified Approach and Comprehensive Experimental Validation." International Journal of Refrigeration 31 (8): 1358-67.

[13] Xerri, S. 2013. "Experimental Investigation on the Effects of Voltage on a Domestic Refrigerator." B. Eng. (Hons) Dissertation, University of Malta. 